De los neogramáticos al tradicionalismo: evolución del pensamiento lingüístico de Ramón Menéndez Pidal ( 1904- 1940 )

Artículo en la Zeitschrift für romanische Philologie, CXXII, 4, 2006, págs. 688-705. 


\section{De los neogramáticos al tradicionalismo: evolución del pensamiento lingüístico de Ramón Menéndez Pidal ( 1904- 1940 )}

El «Manual de gramática histórica española » de Ramón Menéndez Pidal , del que en 2004 se cumplió el primer centenario, constituye la inserción de España y los países hispanos en la lingüística científica del siglo XIX, que con la excepción de la obra de Rufino José Cuervo, habían quedado rezagados de la principal corriente científica de la lingüística del siglo XIX. El «Manual » apareció en 1904 con el modesto título de «Manual elemental de gramática histórica española». Y en efecto su delgadez constituía lo que los anglosajones llamarían un "primer " de gramática histórica.

Por estos mismos años, Ramón y Cajal ( 1899 ) publicó el libro que ha fundado la moderna neurología, «Textura del sistema nervioso del hombre y los animales ». Aunque no son obras comparables, sí son testimonio del ambiente de esfuerzo y de superación de la ciencia española en unos años en que España estaba desalentada por el desastre de 1898.

Menéndez Pidal tenía en ese momento 35 años , pero ya en 1899 había ganado la cátedra de Filología comparada de latín y castellano de la entonces Universidad Central. En 1904 era ya un filólogo conocido y maduro, pues había publicado «La leyenda de los infantes de Lara (1896), obra premiada por la Academia en 1897, y «Crónicas Generales de España » (1898), que le granjearon reconocimiento nacional e internacional. Además había ganado en 1895 con su obra «Cantar de Mio Cid. Texto, gramática y vocabulario», el concurso de la Real Academia Española convocado en 1892 sobre el Poema del Cid, obra que se publicó en 1908. En ella puso a prueba su dominio de las técnicas filológicas y los métodos lingüísticos del siglo XIX, que le habrían de servir para elaborar su «Manual». En 1902 estudió el «Poema de Yúçuf »,que confirmaban su dominio del método filológico y lingüístico.

En la génesis del « Manual », la docencia de la filología comparada latín castellano debió de suponerle un estímulo para salvar el vacío existente en España de una gramática histórica hecha de acuerdo con el método neogramático, tal como exigía la lingüística científica de 1904. Esta es la gran aportación de Menéndez Pidal a la lingüística hispánica, pues el «Estudio elemental de 
gramática histórica de la lengua castellana » del helenista José Alemany (1902), ni la «Gramática comparada » de Francisco Commelerán ( 1889 ), satisfacían esta exigencia epistemológica.

Queremos, pues, destacar que la importancia primordial del «Manual» de Menéndez Pidal para la lingüística hispánica radica en haber incorporado el método neogramático tal como aparece sintetizado en Hermann Paul (1880), y materializado para las lenguas románicas por MeyerLübke (1890) y Gröber ( 1890-1902). La presencia de la «Gramática » del primero y del «Compendio» del segundo es constante, sin que ello merme en profundidad ni originalidad el «Manual».

El panorama de la filología comparada en España hasta 1904 era poco alentador. Rufino José Cuervo (1905,xvii) describe de forma elocuente la situación de la lingüística española hasta la llegada de Menéndez Pidal: «España parecía indiferente a movimiento que tanto le interesaba [ la filología románica y comparada], y aun en nuestros días, sin queja y hasta con aplauso,ha visto salir de sus prensas obras filológicas y etimológicas completamente ajenas a los principios de la ciencia contemporánea. Dichosamente va despertando de su letargo, y Madrid cuenta ya con una cátedra de esta asignatura; los méritos del ilustre profesor que la tienea su cargo alientan dondequiera la esperanza de que pronto se ahuyentarán los vestiglos que vagan todavía en las perezosas tinieblas. \ En esta situación anterior a Menéndez Pidal, los estudiosos antes mencionados habían dedicado parte de su labor a la filología comparada.

Francisco Commelerán (1889) fue catedrático de Latín y Castellano en el Instituto Cardenal Cisneros de Madrid, y miembro de la Real Academia Española de la Lengua,en la que ingresó con un discurso titulado «Las leyes que regulan las transformaciones que en el estado actual de nuestra lengua sufre en su elemento fonético la palabra latina para convertirse en castellano ». En 1889 aparece su « Gramática Comparada de las Lenguas Castellana y Latina ». Se trata de un texto amplio de 645 páginas donde alterna la descripción de la lengua española con la descripción del latín haciendo una comparación sincrónica. Se trata,por tanto de lo que hoy llamaríamos una gramática contrastiva castellano-latín.

En el prólogo, Commelerán expone el clima de entusiasmo científico que suscitó la filología comparada europea en España, los continuados y rápidos progresos que ha hecho,así como la necesidad y utilidad de la filología para la cultura literaria. Señala,además, cómo la gramática comparada se opone a la gramática que él llama tradicional, que, dice Commelerán, « sostiene la imposibilidad de establecer comparación alguna ». Pero entiende que los estudios histórico- 
comparativos, a pesar de sus progresos, son una « verdadera calamidad » para la enseñanza secundaria. Por eso, dedicará lo indispensable a la explicación comparada del castellano.

Con estas advertencias, el castellano es descrito en paralelo con el latín. Así, cuando trata del artículo castellano, afirma que el latín carece de artículo, mientras que el castellano dispone de esta categoría, que concibe como una palabra que se declina según los casos de la gramática latina. Después hace una tímida reconstrucción histórica para obtener la etimología del artículo español. Commelerán no establece leyes fonéticas ni emplea el método comparativo.No obstante hay interesantes observaciones sobre la historia del español, que, en ningún caso son comparables con las reconstrucciones etimológicas sometidas a leyes fonéticas que pocos años después hará Menéndez Pidal.

El segundo estudioso de la filología comparada coetáneo de Menéndez Pidal es José Alemany (1902) filólogo y orientalista, también académico de la Real Academia Española, y catedrático de la universidad de Madrid, que tradujo el «Hitopadesa»y el «Panchatantra». Junto a estas traducciones, escribió la primera gramática histórica del español. En 1902 publicó un « Estudio elemental de gramática histórica de la lengua castellana», que tuvo una segunda edición en 1903,un año antes de que apareciera el «Manual» de Menéndez Pidal.

El « Estudio...» y la primera edición del «Manual...» tienen algunos puntos en común. Alemany, como Menéndez Pidal, divide la materia en dos partes: Fonología ( Alemany), Fonética ( Menéndez Pidal),y Morfología ( tanto Alemany como Menéndez Pidal). La fonología de Alemany contiene muchos menos datos históricos que el «Manual» de Pidal, aunque Alemany conoce bien los procesos fonéticos que actúan en el cambio, como metátesis, vocalización, diptongación etc. Alemany caracteriza los cambios fonéticos en términos de reglas, equivalentes a leyes fonéticas.Pero el mecanismo detallado de los cambios fonéticos que ofrece Alemany es por lo general vago. Explica así el cambio de e abierta acentuada en el diptongo je ( $\$ 373$ y 4): «El diptongo ie se reduce a $e$ cuando le precede consonante palatal.En este caso la i se funde con la palatal ( LEVAT $>$ lieva $>$ lleva). El diptongo ie se reduce a $i$ si le sigue palatal.»

Comparemos esta ley con la descripción de 1904 de Menéndez Pidal (§10-2): «El diptongo ié, por medio de una dislocación del acento, se redujo posteriormente a $i$, como saEculum $>$ siglo... ( \$112bis-3): LeVARE en la Edad Media se conjugaba etimológicamente liévo,liévas,...; ly- se pronunció $l l$. y se extendió a todo el verbo ». Alemany deja muchas evoluciones sin desarrollar.Así, en la palabra vinDEMIA, con $e$ larga que resulta en vendimia, no se da cuenta, 
como hace Menéndez Pidal en 1904, de que se reduce a $i$ por efecto de la yod siguiente. En consecuencia,considera que esa $i$ procedente de $e$ larga no está sometida a regla.

La evolucion de $f$ - inicial latina en Alemany nos da una idea del poquísimo desarrollo de este «Estudio... ». Sólo indica ( § 75) que « inicial ante vocal no labial,persistió en castellano antiguo;la aspiración labial que representaba pasó a gutural y sufrió la misma suerte que h, por cuyo signo fue sustituda ante vocal no labial hacia fines del siglo XIV .»

La gramática histórico- comparativa fue la creación de la filología alemana del siglo XIX. En su constitución, llevada a cabo a lo largo de todo el siglo XIX, se pueden distinguir dos partes. La primera es la que corresponde a su iniciación con Bopp y Grimm, que son los paleogramáticos. Su teórico es Guillermo de Humboldt.

La segunda corresponde a la consolidación del método comparativo a través de la crítica hecha a los paleogramáticos por Osthoff y Brugmann, que son los neogramáticos. El teórico de la gramática histórico - comparativa de los neogramáticos es Hermann Paul, que recoge además, parte del legado de Guillermo de Humboldt. Esta síntesis es expuesta en los «Prinzipien der Sprachgeschichte $»^{1}$, libro que lamentablemente no ha sido traducido al español.

La teoría lingüística que subyace al « Manual de Gramática Histórica » ${ }^{2}$ es básicamente la expuesta por Paul en los «Prinzipien», cuya primera edición es de 1880, y la útima es de 1920.Nos referimos a este libro con la letra P y el parágrafo que corresponda.

Paul afirma que el lenguaje como producto de la cutura humana es objeto de la observación histórica, pero en paralelo a la historia del lenguaje se necesita una ciencia que se ocupe de las condiciones generales de su objeto, que investigue la naturaleza y las operaciones de los elementos que permanecen constantes en el cambio lingüístico. Precisa que esa ciencia debe recurrir a la psicología y a la fisiología. En efecto, Paul establece ( frente a los paleogramáticos) que el elemento psíquico de la cultura, y por tanto,del lenguaje, es el factor esencial de las ciencias de la cultura, pero no es el único factor.Hay que acudir al factor físico, que en el caso del lenguaje es la fisiología articulatoria de los sonidos. La mente, dice Paul, trabaja en armonía con el cuerpo ( P § 4 ), y, más específicamente, la doctrina de los principios que elabora Paul tiene que exponer cómo cooperan los factores físicos y psíquicos para una finalidad común.

El aspecto psíquico del lenguaje lo constituyen las imágenes mentales, o representaciones subjetivas (Vorstellungen ), mientras que los sonidos son la parte física, que sirven para evocar 
en otra mente las imágenes mentales que aquéllos llevan asociadas. El carácter de esa asociación sonidos-imágenes es indirecto, no directo ,como lo es un grito de dolor. Los sonidos además de símbolo de las imágenes mentales ( $\mathrm{P} \S 12$ ), están asociados a su vez a los movimientos articulatorios necesarios para producirlos. Los sonidos tienen la única función de transmitir los efectos de un organismo psíquico individual sobre otro ( P § 14 ).

El sonido articulado es por tanto, independiente de la imagen mental a que está asociado o del significado. Este puede considerarse un principio esencial de los neogramáticos incorporado hoy a la lingüística moderna. Menéndez Pidal lo recoge en el «Manual» ( 1904 , § 69) con una sugestiva metáfora: «Podemos representarnos el sonido y el pensamiento como dos relojes isócronos que marchan uniformes, pero sin influir el uno sobre el otro, o como dos líneas paralelas que nunca se tocan $»$

El segundo principio neogramático expuesto por Paul en el cap.III de los «Prinzipien» establece que los cambios fonéticos obedecen a leyes fonéticas uniformes ( P § 46 ) .Los cambios se deben a una desviación (Verschiebung) gradual de una norma articulatoria ( $\mathrm{P} \S 45$ ) impulsados por el menor esfuerzo articulatorio, o Bequemlichkeit ( $\mathrm{P} \S 38$ ) y cuyo dominio de aplicación es un dialecto en una sucesión de periodos de tiempo histórico. Las excepciones a una ley fonética uniforme se deben a procesos psicológicos espontáneos ( no a desviaciones de una norma articulatoria). Estos procesos ( $\mathrm{P} \S 45$ ) son : (i) metátesis, (ii) asimilación, (iii) disimilación, (iv) analogía ${ }^{3}$ (P §§ 75-84), (v) etimología popular (P §§ 150-158),(vi) contaminación (P §§110-121), y (vii ) error lingüístico ( P §81) .

Los procesos i-vii, según Paul, no causan el cambio fonético histórico ( Lautwandel) porque no constituyen una desviación de la articulación, sino que son de naturaleza puramente psicológica.Introducen no un cambio sino una sustitución fonética (Lautwechsel). Fiel a este segundo principio ,en la primera edición del « Manual de Gramática Histórica », de 1904, Menéndez Pidal describe en los capítulos II y III el desarrollo de las vocales y consonantes del latín (hablado) al español «considerando cada sonido como cosa aparte y aislada, que evoluciona y se transforma de un sonido latino en otro correspondiente castellano» (Menéndez Pidal, 1904, § 64).

Esta afirmación recoge puntualmente el principio de ley fonética que aparece en las primeras páginas del «Manual » (1904, § 4.5$)$ afirma que « las otras hablas de España más afines al castellano y que se confundieron con él para formar la lengua literaria ... tienen la mayoría de sus 
leyes fonéticas comunes con el castellano » .

Las leyes fonéticas son concebidas al modo neogramático como uniformes,o sin excepciones. Así, en el § 23 de 1904 formula una de estas leyes: «la vocal a ( tónica ) se conserva siempre. Se puede decir que esta ley no tiene excepciones ( a no ser en voces exóticas ) ».

En la teorización de Paul, la ley fonética tiene como resultado un cambio fonético causado por una desviación articulatoria gradual, no una sustitución fonética (Lautwechsel). Si al comparar palabras de un mismo dialecto a lo largo de dos fases diacrónicas se observa que el cambio no es gradual, entonces ha operado alguno de los procesos psicológicos, que causan la excepción, en particular la analogía.

De la misma manera, Menendez Pidal ( $1904, \S 64)$, precisa las razones de la irregularidad. Por un lado, afirma: « La regularidad de esta evolución se ve turbada no pocas veces, pues los sonidos no viven así aislados como los hemos estudiado, sino formando palabras; y al tener que pronunciarse juntos varios de esos sonidos cuyo desarrollo individual hemos visto, no puede menos de suceder que unos influyan sobre otros, pues la lengua, al ponerlos en contacto, procura allanar esas dificultades de pronunciación, y así se producen varios fenómenos hijos de la influencia de un sonido sobre otro. ». Pero por otro lado, puntualiza que « la palabra no es sólo un producto acústico de la garganta y de la boca, sino que representa ideas, y no es extraño que la idea influya sobre los sonidos, pues el que habla procura a veces asemejar por su forma aquellas palabras que tienen alguna semejanza en su significación, y así se producen varios fenómenos que obedecen a la influencia de unas palabras sobre otras.»

El diseño de gramática histórica de 1904 aplica el método neogramático de una forma impecable, y se mantiene así, como veremos, hasta 1925. Primero, determina las leyes fonéticas para vocales y consonantes, y después estudia los procesos psicológicos ( que unas veces llama accidentales y otras esporádicos) que escapan a las leyes previamente determinadas. Así el capítulo IV de 1904 contiene el estudio de los procesos de asimilación, disimilación y metátesis, en la línea ortodoxa neogramática. Además, desde 1905 hasta 1918, introduce un nuevo concepto de proceso de sustitución fonética, que es el de «añadidura de sonidos», incluido bajo el título de « fenómenos especiales que influyen en la evolución fonética .Es el caso de sonidos epentéticos [ b ] o [ d ] en la evolución de но́міNem > homne > hombne > hombre, donde el sonido [ $\mathrm{b}$ ] se desarrolla como prolongación de [ $\mathrm{m}$ ] o [ d ] como prolongación de $[\mathrm{r}]$ en la evolución de INGENERARE $>$ engenrar $>$ engendrar. 
A partir de 1925 la epéntesis forma parte de los cambios fonéticos esporádicos y es categorizada como un fenómeno de fonética articulatoria al tratarse de un «refuerzo de la articulación ».

La analogía es el instrumento conceptual que más relevancia tiene en la teoría neogramática de Paul. La razón de ello se encuentra en que la analogía es el procedimiento que para los neogramáticos permite crear nuevas pronunciaciones, nuevas palabras y nuevas frases. Paul dedica todo el capítulo 5 de los «Prinzipien» a la analogía, destacando que las palabras individuales se atraen unas a otras en la mente humana. Esta atracción recíproca depende de una correspondencia parcial del sonido o del sonido y el significado simultáneamente.

El « Manual » $(1904, \S 69)$ recoge fielmente el principio de influencia analógica, añadiendo algunas importantes reflexiones sobre el signo lingüístico. Afirma Pidal,en primer lugar, que la relación entre el sonido y el significado es convencional (y desde la edición de 1905 afirma que la relación es arbitraria ): «El sonido y el pensamiento que forman el lenguaje son de naturaleza tan distinta, uno material y otro espiritual, que están entre sí en la relación del signo a la cosa significada, es decir, en una relación puramente convencional, siendo indiferente cualquier sonido para representar cualquier idea, y cualquier idea para encarnar en cualquier sonido.» Pero a continuación precisa, como lo hace el teórico de los neogramáticos, que el sonido puede influir sobre la idea : «No obstante, hay casos en que la palabra no siempre se limita a ser signo indiferente del pensamiento , sino que arrastra a la idea, y así de las palabras nacieron mitos y leyendas antiguas, y las palabras sugieren retruécanos y otros juegos de vocablos».También la idea puede influir sobre el sonido: «El pensamiento no se limita a usar de la palabra como de signo indiferente, sino que lo amolda a su gusto, invadiendo el campo de la evolución fonética para violentar su desarrollo natural; estas intrusiones del pensamiento en la fonética obedecen al deseo de hacer resaltar con el sonido la analogía verdadera o supuesta que se descubra entre dos o más voces, avecinando el sonido de una al de otra o confundiendo en una dos voces de significado análogo . »

En 1918 precisa que esas intrusiones del pensamiento en la fonética vienen del deseo de los hablantes, por lo común inconsciente. Este carácter inconsciente de los procesos de desplazamiento fonético y de influencia analógica, y en general de todos los procesos lingüísticos, fueron siempre destacados por Paul ( P § 69 ).

Es importante notar para el estudio de la formación del pensamiento lingüístico pidaliano cómo a partir de 1925 la doctrina neogramática tan firmemente sustentada hasta esa fecha 
comienza a sufrir un proceso de reflexión. Primero, aparece en el « Manual» la teoría del tradicionalismo, que el filólogo español propuso a propósito de los cantares de gesta, y que adopta decididamente en « Orígenes del español » de 1926. Segundo, en 1925 aborda con un nuevo espíritu el estudio de los cambios esporádicos, que hasta esa fecha los había considerado de poco interés histórico, aunque necesario (« Manual »,1918, §64); ahora esos cambios son objeto de reflexión sobre la teoría neogramática.

El tradicionalismo, en la redacción pidaliana del «Manual » $(1925, \S 64)$, sirve para matizar la férrea posición neogramática : «... hemos visto [ en el capítulo II y III ] principalmente la historia del trabajo muscular del aparato vocal en cuanto articulador de la palabra, regido,pues, por una actividad psíquica más o menos consciente; es decir, hemos visto la historia de la articulación del latín, como expresión de un fenómeno espiritual, claro es, pero sometida a muy determinadas normas fisiológicas y a muy poderosas corrientes tradicionales que obraron sobre la colectividad hispánica.... ». Más adelante («Manual», 1925, § 68) insiste en que la relación de arbitrariedad del signo es una relación : «afirmada por una larga tradición.No obstante, hay muchos casos en que el pensamiento no se limita a usar de la palabra tradicional como de signo indiferente, sino que la amolda a su gusto...»

La introducción del concepto de tradición es además resultado del estudio del español primitivo hasta el siglo XI, objeto de la obra «Orígenes del español », de 1926. En ésta, Menéndez Pidal mantiene el concepto de ley fonética de los neogramáticos, pero con matizaciones importantes, que le aparta de ellos. En efecto, dice Menéndez Pidal ( 1926, § 111-2) en alusión a la doctrina de Paul:« Se ha buscado el principio de evolución del lenguaje en cada cambio de generación », pero lo que sucede es que : «Muchas generaciones consecutivas participan de una misma idea innovadora y la van realizando persistentemente, a pesar de pequeñas variantes en el modo de concebirla; constituyen una tradición nueva, en pugna con otra tradición más antigua ». Por tanto, aquí se aparta del principio neogramático de Paul ( P § 18), que afirma que los cambios lingüísticos se efectúan en parte en el individuo a través de su actividad espontánea, mediante el hablar y el pensar en las formas del lenguaje, y en parte por el influjo que cada individuo recibe de otros individuos. Además, continúa Paul, esas influencias son especialmente importantes en el momento del aprendizaje del lenguaje ( P § 18 ), pues son los procesos de aprendizaje del lenguaje de la mayor importancia para la explicación del cambio lingüístico. Al comparar dos épocas divididas por un largo espacio de tiempo, de las que decimos que el lenguaje ha 
cambiado en tales puntos del tiempo, lo que ha sucedido es que el lenguaje ha experimentado una nueva creación,que no es idéntica con la primera creación.

La afirmación de que el cambio lingüístico está inserto en una tradición de muchas generaciones, y no, como sostiene la doctrina neogramática, que es una creación individual que incorporan los que aprenden el lenguaje, constituye un cambio conceptual de enorme importancia en el pensamiento lingüístico de Menéndez Pidal incorporado al « Manual »en 1925.Pero Menéndez Pidal ( «Orígenes...», §112 ) va más allá en el concepto de tradición y de continuidad tradicional, pues la tradición es una fuerza que se impone al individuo creador de los neogramáticos . La continuidad tradicional en el lenguaje, dice Pidal: " Resulta más evidente, por estar sus evoluciones menos sujetas a la pura iniciativa individual, a causa de intervenir en ellas la totalidad de la colectividad hablante...la innovación lingüística individual tiene así que vencer la resistencia que le ofrece la inmensa masa de hablantes apegados a una tradición arraigada.»

La tradición pidaliana no es más que un hecho colectivo equiparable a la « langue» de Saussure. Por eso, estas palabras sintonizan con la reacción antineogramática de un joven Roman Jakobson ${ }^{4}$ en un temprano escrito de 1925, que se revolvía contra el individuo innovador de Paul: « Un producto típico del realismo ingenuo fue la tesis tan difundida de los neogramáticos, según la cual única y exclusivamente el lenguaje individual es el lenguaje real. Llevada hasta el epigrama, esta tesis sostiene que en última instancia sólo la lengua de una persona determinada, en un momento determinado, representa una realidad auténtica, en tanto que todo lo demás no pasa de ser una abstracción teórico-científica. Nada más ajeno a los modernos empeños de la lingüística que semejante tesis, que fue uno de los pilares fundamentales de la escuela neogramática.Al lado del acto individual, particular del habla, la lingüística moderna conoce también la langue, esto es un conjunto de convenciones necesarias $.1)$

En cuanto a los cambios esporádicos, éstos habían tenido un papel casi marginal hasta 1925 en el estudio de la gramática histórica. En esta fecha le sirven para una importante reflexión teórica, que hasta entonces no había formulado. Se trata del alcance de las leyes fonéticas. Menéndez Pidal ( «Manual »,1925, § 64) se muestra, por principio, neogramático porque : «El descubrimiento de esas leyes fonéticas ha sentado el estudio del origen de las palabras sobre una base firme, capaz de sustentar el pensamiento científico;ha dado evidencia a la 
etimología que antes era sólo un hacinamiento de hipótesis desarticuladas entre sí... ». Ahora bien, ¿ cuál es la naturaleza de los cambios esporádicos ? La respuesta del filólogo español sigue la senda de los neogramáticos, pero con alguna duda:«Alguno de estos cambios esporádicos son de igual índole que los regulares, es decir, se refieren al modo en que los centros nerviosos dirigen el trabajo muscular del aparato vocal; algunos de esos cambios hasta tienen un campo de acción tan extenso, que llega a ser difícil establecer el punto de separación que podemos establecer entre ellos y los cambios regulares. ».

En consecuencia, se le plantea una duda aparentemente irresoluble: « $i$ Debemos llamar regular, o esporádica, la inflexión de la $o$ por efecto de una yod siguiente ? Pero otros muchos cambios esporádicos son de naturaleza visiblemente distinta de la de los regulares, por fundarse en una intervención más pronunciada de las actividades psíquicas individuales que desvían la articulación de un modo brusco, muy diverso del modo suavemente gradual.... en los cambios regulares. » Concluye, en fin, con la adopción del principio metodológico de que los cambios esporádicos son «cambios debidos a otras leyes o principios de menos generalidad o extensión .» Este principio no hace sino reforzar el principio de regularidad de las leyes fonéticas de los neogramáticos , pues como afirma Szemerény (1978, 42 ) a propósito del papel de la ley de Verner en el desarrollo de la teoría lingüística neogramática : «Si los cambios esporádicos alegados se revelan siempre como regularidades de otro tipo, se llega a la conclusión de que todo cambio fonético propiamente ha de concebirse como regular.» Este principio de regularidad constante en la evolución histórica es el que Pidal adopta finalmente en la versión final del «Manual» de 1940 .

Otro concepto de alcance introducido en 1925 es el de ultracorreción .Es una forma especial del concepto de Ueberentäusserung o ultraenajenación de Theodor Gartner ( 1843 -1925), que, según Walter von Wartburg (1951, 47 ), lo acuñó en su Rätoromanische Grammatik,de1883. En el « Manual » $(1925, \S 71$ ) define de este modo el concepto : «Llamaremos así un fenómeno fundado en el deseo de purismo. A menudo conviven en el lenguaje usual dos formas, una correcta y otra vulgar...por ejemplo, comido,comida ... conviven hoy con otras en que se pierde la $-d$ : omío, comía. Cuando el que habla es de poca cultura ... los más cultos intercalan $d$, se equivoca, y cree que en vez de mío, tardío, correo, Bilbao, debe decir, para hablar bien, mido, "fruta tardida', "el correo de Bilbado "». Menéndez Pidal emplea el concepto de ultracorrección en 1925,como consecuencia del estudio del español primitivo llevado a cabo en 
Orígenes del español. En esta obra ( $§ 110$ ) afirma que: « Muchas de las formas de los documentos primitivos, muchísimas son ultracorrecciones. De no apreciarlas como tales, quedarían inexplicables.» El recurso a la ultracorrección le permite explicar aparentes desviaciones o contraejemplos a una ley fonética. Es el caso de la aparente conservación de consonantes oclusivas sordas en documentos mozárabes, que Meyer- Lübke ( 1924) consideraba como ejemplos reales de conservación, mientras que Menéndez Pidal ( 1926, § 46 4-d ) mostró que se explicaban como ejemplos de ultracorrección . El fenómeno de ultracorreción sobrepasa el aparato conceptual de la teoría neogramática, porque tiene naturaleza sociológica, no psicológica individual : un hablante sabe varias normas sociales de hablar o escribir, y elige una porque cree equivocadamente que es más prestigiosa, correcta o purista que otra.

En 1940 ( § 68), introduce, junto a los conceptos ya tratados de tradición, de regularidad constante, y de ultracorrección, el de contaminación : «Sin embargo, hay muchos casos, en que el hablante no se limita a usar de la palabra como de signo indiferente fijado y animado por la tradición, sino que la contamina con alguna otra representación psíquica concurrente que viene a alterar la articulación de la palabra.»

El concepto de contaminación ( Kontamination ${ }^{5}$ ) es definido por Paul ( P § 110) como el proceso en que dos formas de expresión sinónimas o de algún modo emparentadas se arrastran una a otra en la consciencia de modo que ninguna de ellas se impone, sino que surge una nueva forma, en la que se mezcla un elemento de una con un elemento de otra.Uno de los ejemplos de contaminación de Paul es el de la serie de días de la semana, donde lunes y miércoles sufren la contaminación de martes (MARTIS), jueves (JOVIS) y viernes (vENERIS). Este mismo ejemplo aparece también en el « Manual » desde 1904, pero sólo como contaminación desde 1940.

Otros cambios significativos introducidos en el « Manual...» en 1925 se refieren a la analogía. Hasta esta fecha, agrupa bajo el titulo «Influencia de una palabra sobre otra » tres procesos psicológicos :(a) la etimología popular, (b) la analogía de unas voces con otras , y (c) la fusión o cruce de dos voces. En 1925 , el título « Influencia de una palabra sobre otra » agrupa el proceso de fusión de voces, con dos apartados.En el primero, trata como fusión la evolución de palabras que forman series como nURUS y socra ; la evolución de nURUs hacia * nora, con $e$ breve, y de aquí, nuera, es una caso de fusión, mientras que en el segundo apartado trata de 
otras fusiones ( o cruces ) de palabras que no forman serie. Esta reorganización parece recoger la categoría de cruce (Verschränkung) que empleó Meyer-Lübke (1890, I ) al tratar la formación de nuevas palabras,como esp.aullar $<$ eJulare + ululare, según explica el filólogo alemán.

Junto a la analogía, la etimología popular es otro de los principios causales de naturaleza psicológica, propio de la teoría neogramática, que inciden en la historia del lenguaje. Es tratado con detenimiento por Paul (P $\S \S 75-77$ y $\S 150$ ). El concepto de etimología popular ( Volksetymologie ) fue acuñado por Ernst Förstemann ${ }^{6}(1822-1906)$ y fue rápidamente adoptado por la lingüística histórica de la segunda mitad del siglo XIX . Así, Meyer-Lübke (1890, I, passim ) lo utiliza de forma persistente para las excepciones a las leyes fonéticas,como por ejemplo, en la explicación de it.chiodo, resultante de la asociación de clavus con CLAUDERE, y muchos más ejemplos en el vol.I.

Paul ( P § 150) distingue dos formas de etimología popular. Una, simple, que define como una transformación (es decir, una metainterpretación ) del significado efectuado por la conciencia idiomática del hablante ( Sprachgefühl). La segunda es una forma compleja, que es la que emplea Menéndez Pidal. La forma compleja es caracterizada por Paul( P § 151), como una transformación por la que una palabra A que nos recuerda a otra B por la similitud fonética, se le hace fonéticamente más parecida a $\mathrm{B}$.

En 1904 Menéndez Pidal define la etimología popular como la actividad consciente del hablante que busca una conexión etimológica a una palabra, expresión que recuerda la de Paul (P §76 “Wörter die in etymologischen Zusammenhange stehen” ) : Las palabras más usuales y corrientes de la lengua se pronuncian por el pueblo viendo en ellas intimamente encarnadas su significación; así que el pronunciar una palabra no tan corriente y que tiene alguna apariencia rara, bien sea por su configuración o agrupación poco común de sonidos, bien sea por su grande extensión, le produce una impresión de extrañeza y quiere hallar en esa voz aquella transpariencia que descubre en las familiares,....si entonces advierte cierta semejanza de sonido entre esa voz obscura y otra de las conocidas, piensa que hay entre ambas alguna conexión etimológica. »

Entre 1904 y 1925 la etimología popular tiene como dominio la forma fonética de la palabra, y es considerada como una forma de analogía ( no proporcional) que actúa sobre los sonidos de palabras entre las que el hablante establece una conexión etimológica que es históricamente 
inexistente.En 1925 cambia completamente la categorización de la etimología popular como analogía, y la presenta bajo la categoría más amplia que llama « error lingüístico», que concibe de esta manera: «El error,la falsa interpretación de los fenómenos lingüísticos, es un importante factor en la evolución del lenguaje, y aunque su estudio ha sido muy descuidado hasta ahora,debe formar un capítulo aparte... La etimología popular es, pues, como un cruce de palabras procedente de un error de interpretación respecto de una de ellas; el que habla cree equivocadamente que entre ellas hay una conexión etimológica .»

Subclases del error lingüístico son también para Pidal la ultracorrección y la equivalencia acústica. Pero la ultracorrección tiene carácter sociológico, como hemos dicho antes, mientras que la equivalencia acústica es un error de percepción auditiva . El error lingüístico forma parte de la teoría neogramática. Paul recurre al error lingüístico para el caso de ciertas formaciones analógicas.Así, en las formaciones analógicas proporcionales se pueden producir errores de producción lingüística cuando la forma analógica produce una forma que choca con una forma memorizada. También Paul estudia el error de percepción acústica (Verhören),pero niega rotundamente $(\mathrm{P} \S 48)$ que el error de percepción tenga efecto alguno en la historia de la lengua. Por el contrario, Menéndez Pidal en 1925 ( § 72) afirma que: « Muchos cambios fonéticos se fundan en un error de audición. Hay a menudo, cuando se trata de palabras poco conocidas, un error de percepción debido a cierta equivalencia de unos sonidos con otros. El oído, al escuchar una palabra poco habitual, puede equivocarse, oyendo alguno de sus sonidos diferente de como se ha pronunciado...». Las investigaciones fonéticas de L.Gauchat ( 1925) y de Panconcelli-Calzia (1924), debieron de influir decisivamente en la consideración del error acústico como factor del cambio fonético.

La introducción del concepto de error acústico, junto con los ya vistos de ultracorrección y sincretismo de las leyes fonéticas, aumenta el poder descriptivo del « Manual» de una forma que sobrepasa el marco restrictivo de la teoría neogramática, asentado en la hipótesis de la regularidad del cambio lingüístico y de la inexcepcionalidad de las leyes fonéticas. .

De esta manera, en el «Manual...» de 1925 se abordarán problemas que el marco más restrictivo de los principios neogramáticos hacía difícil tratar. El aumento del poder descriptivo le permite ofrecer varias explicaciones a las etimologías. Así, la evolución de $s$ - inicial latina en palabras como SAPONE, SUCU, Y SEPIA, recibe una explicación tanto en términos de equivalencia acústica.. El resultado de lat. $s$ - es en algunas palabras la consonante velar fricativa [ $\mathrm{x}$ ], una 
anomalía a la ley fonética que rige el destino de $s$ - inicial del latín al español. Para explicar el cambio, en 1925 ( § 72.2) sostiene que es consecuencia de la equivalencia acústica entre [ s ] apicoalveolar cóncava castellana y la prepalatal [̌̌s]. Pero no elimina una explicación sociohistórica, mantenida desde 1904, como expondremos más tarde.

Junto a las causas articulatorias, psicológicas, y sociolingüísticas que en el marco conceptual va progresivamente introduciendo Menéndez Pidal, actúan otras, que el filólogo español introduce en la dirección histórica o sociohistórica. Una de estas causas históricas es el contacto de lenguas en la Península Ibérica.

Un primer ejemplo de causa histórica en la historia del español es el de la evolución de $f$ inicial latina. En 1904 afirma que se conservó hasta el siglo XV y fue sustituida por la aspirada [ h ] en los ss XV y XVI. En 1905 es más preciso y hace notar que $f$ - se conservó en la lengua escrita hasta fines del siglo XV, luego sustituida por $h$, así representa la aspiración. Ya en 1905 añade que es importante la cuestión de la pérdida de la $f$-, y observa que en la lengua escrita no ocurre hasta el siglo XV, pero supone que no hizo más que generalizarse una pronunciación que antes era dialectal. Además, lanza la hipótesis que la pérdida de $f$ - es « hija de una influencia ibérica ». En la constitución de la lengua española, Menéndez Pidal distingue desde 1904 una categoría de lenguas ibéricas, que mantiene hasta 1940. Son todas las lenguas prerromanas, entre las que incluye el vasco . Pero si en 1904 ( § 4.1 ) afirma solamente que « la influencia de las lenguas ibéricas es muy escasa y dudosa», desde 1905, aun mostrándose escéptico sobre la influencia de las lenguas ibéricas por ser entonces muy poco conocidas, adopta la hipótesis del vascoiberismo de Wilhem von Humboldt, pues afirma ( 1905, § 4 ) que: «Uno de los rasgos de la lengua ibérica que pueden señalarse es la carencia de f y v en ciertos dialectos ( el vizcaíno moderno pronuncia pigura figura, pama [fama], baba faba) y como los vascones habitaban al Norte y Sur de los Pirineos, es notable que los romances hablados en Gascuña (=Vasconia) y centro de España pierdan la finicial pudiendo achacarse esto a influencia ibérica. ». Su adhesión al vascoiberismo llega hasta 1940, donde cataloga al vasco como « lengua neoibérica conservada». En esta adhesión persistente al vascoiberismo están muy presentes los trabajos de Schuchardt ( 1906,1907 ) y Saroïhandy ( 1913 ), entre otros .

Otro factor histórico que puede alterar la actuación de la ley fonética es la influencia morisca en la fonética hispana. Ya Meyer Lübke (1890, I, § 417 ) había observado que la evolución de sinicial a [ ̌ s ]en español no estaba clara, y en general la evolución de lat. $s$ - a $\breve{s}$ - en los romances 
se debía a causas especiales. En 1904 Menéndez Pidal ofrece una primera explicación a la observación del filólogo alemán afirmando que la fricativa [ $\mathrm{s}$ ] alguna vez muda en el sonido prepalatal fricativo [ $\check{\mathrm{s}}$ ] escrito “ $\mathrm{x}$ “, mutación procedente de la pronunciación morisca de las palabras sucum (jugo), sePIA ( jibia) y SAPONEN ( jabón).

Hasta 1940 vemos cómo evoluciona el pensamiento lingüístico de Menéndez Pidal ampliando la explicación de las etimologías en términos no sólo neogramáticos,sino también en términos sociolingüísticos y sociohistóricos, alejados de aquéllos. Pero las explicaciones de fonética fisiológica son, sin embargo, constantes; lo que muestra su adhesión a la teoría neogramática, que emplea más como brújula que como dogma. Así, la yod va ganando en poder explicativo desde 1904 cuando se introduce por vez primera, y que define como « una $i$ o $e$ hiato ». En 1904 el uso de la yod es restringido.En esta fecha, [ e ] breve no diptonga en sex porque le sigue «una gutural acompañada con otra consonante», pero en 1905 esa [ e ] breve no diptonga porque le sigue una yod. En 1904 [ o ] abierta del latín vulgar no diptonga « cuando le sigue una gutural agrupada con otra consonante que se transforman en un sonido palatal como ch o j $»$.

Esta explicación pervive hasta 1940 donde afirma, reuniendo los casos de [ e ] y [ o ] breves : « La O [ breve ] lo mismo que la E [breve] deja de diptongarse bajo el influjo de una yod ». En 1904 [ o ] cerrada del lat.vulg. " se reduce a veces a u cuando le sigue un grupo de consonantes, de las cuales la primera es una gutural o 1 , que se transforma en palatal». Pero en 1905 el cambio [ o] > [ u ] se debe « a una yod procedente de un vocalización de gutural o $1 »$.

La función de la yod va adquiriendo peso en la elaboración de las etimologías.Hasta 1940 la evolución coriu > cuero es resultado de la combinación de [o ] cerrada con [i ] en hiato, atraida de la sílaba siguiente. En 1940 las distintas subclases de yod explican las modificaciones de [ o ] cerrada. Pero en algunos casos las correcciones vacilan, pues sólo en 1940 la evolución es explicada como resultado de una yod atraida por la sílaba siguiente. Finalmente, en 1940. introduce un párrrafo entero, el 8bis, donde categoriza la yod ( que hasta 1940 era tratada básicamente desde el punto de vista de sus orígenes ) en cuatro categorías en función de sus efectos y su génesis histórico-temporal: yod primera, segunda, tercera y cuarta. Introduce, además, la categoría wau para la semivocal [ u ]. En consecuencia, en 1940 la evolución del vocalismo latino al español adquiere un carácter más sistemático.

Esta elaboración de la categoría yod a lo largo de treinta y seis años prueba cómo el «Manual...» ha ido formándose con cautela a la vez que con precisión, pues las evoluciones de los 
sonidos han sido continuamente revisadas.Así, en 1904 establece una ley fonética referida al diptongo latino [au ] dentro de la evolución de o larga y u breve:«El diptongo au es también o, MAURUM > moro ». En 1905 es mucho más preciso, y añade : «Esta reducción de au à o no es primitiva en romance; aunque era fenómeno dialectal latino que aparece en las inscripciones de España como en las de otras regiones(closa Plotus ), la lengua literaria impuso generalmente el au .... pero esta confusión en castellano es posterior a la sonorización de la consonante sorda intervocálica ». En 1918, sin embargo, el diptongo [ au ] aparece dentro de la evolución de a +u, y lo explica en términos de fonética fisiológica: « Si a la A sigue una U se busca también acercamiento entre la vocal extrema abierta a y la extrema cerrada $\mathrm{u}$, y podemos establecer los grados $\mathrm{a}+!, \mathrm{o}+!, \mathrm{o}+\mathrm{o} »$.

La cautela para explicar los casos resistentes a las leyes fonéticas es una constante. Así, en 1904 ( § 20.3) recoge un conjunto de casos inexplicados a la ley que establece que $u$ y $o$ breves átonas del lat .vulg.= esp. u , como localem > lugar, RUGitum > ruido, y otras más. Hasta 1940 no propone ninguna explicación,y considera estos datos como inexplicados. Sólo en 1940 afirma que estos casos que no cumplen la ley « obedecen a la mayor indecisión de la vocal inacentuada.»

Un ejemplo excelente de estas explicaciones de fonética fisiológica es el de la reducción del diptongo [ ue ] a [ e ] como en culuebra > culebra. En 1905 [ u ], que es labial, se pierde por estar entre elementos de articulación anterior 1...r. Desde 1918 la explicación articulatoria es mucho más detallada. La [ u ] se pierde porque : « La alternativa de un sonido labial+alveolar $(1, r)$ +labial (w) +palatal ( e ) provoca una disimilación eliminadora que excluye el segundo sonido labial, el cual siendo a la vez velar o posterior, ve dificultada su articulación por ir entre dos sonidos que exigen una postura contraria de la lengua como producidos en la parte anterior de la boca: r....r, 1...e .». En 1925 amplía esta explicación a casos como NORONIA $>$ Norueña $>$ Noreña. El propio Pidal observa un posible contraejemplo a esta explicación. Se trata de la evolución de SORBU $>$ swerba $>$ serba . Pero el contrajemplo es salvado al determinar que la desaparición de $w$ obedece al efecto disimilatorio de eliminar el sonido labial $w$ entre sonidos palatales $s$...e . Las correcciones no son, sin embargo, completas. Así, la evolución de [ a ] átona + [ i ] atraida $(1905, \S 17$ ), como BAJSAR < BASJAR , se explica siempre como resultado de una mezcla de $\mathrm{a}+\mathrm{i}$ atraida de la sílaba siguiente, sin indicar que se trata en realidad de una yod cuarta atraida.

La prosecución del principio neogramático de la inexcepcionalidad de las leyes fonéticas enfrenta 
a Pidal con escollos insalvables. Por ello echa mano de conceptos de la lingüística idealista, que le permiten transceder el marco rígido de las leye fonéticas. Entiende que las leyes fonéticas pueden verse esquivadas por imposiciones estéticas que se refieren a preferencias de los hablantes por ciertos sonidos en lugar de otros, o bien por una tendencia a identificar el tema de la palabra. Así, el cambio anómalo de latín [ o ] breve átona y [ o ] cerrada del vulgar, en colostro > calostro , permanece como una mera constatación hasta 1940, donde introduce una explicación estética, según la cual el cambio o > a se debe « a cierta preferencia otorgada a la a inicial como vocal más clara ».

Las explicaciones en términos estéticos recurren también a la idea de "gusto lingüístico ", concepto nada neogramático, como el de preferencias de los hablantes. Esta es la explicación que en 1940 ofrece de por qué no ha monoptongado [au ]: «Cuando se vocalizó la L agrupada tardíamente con otra consonante, por pérdida de la vocal postónica, ya se habían extinguido las generaciones dominadas por el gusto lingüístico de la monoptongación, y así c a l i c e, s a 1 i c e dieron cauce y sauce $»$.

En el « Manual » de 1940, cuando la teoría lingüística neogramática había dejado de ser dominante en el panorama de la lingüística, Ménendez Pidal ha relajado su firme temprana actitud neogramática de 1904 resultado de su propia investigación en lingüística histórica. Así ocurre con el problema de la caída de vocal postónica. En 1904 ( § 26.2 ) mantiene que: «La postónica interna se conserva algunas veces; el caso más corriente es cuando la pérdida de la final vino á hacer imposible la de la protónica ARBOR (EM) > árbol ; HOSPIT (EM) > huésped, ...». Esta explicación adopta lo que en la moderna fonología sería la ordenación de sangradode las reglas o bleeding order de Kiparsky ( 1968 ) de modo que la aplicación de la ley ( regla) A impide la aplicación de la ley (regla) B. La ley de caída de postónica interna sería bloqueada por la previa aplicación de la ley de pérdida de la final. Pero desde 1905 y hasta 1925 cambia la explicación neogramática en términos de leyes fonéticas y mantiene que la pervivencia de la postónica interna en árbol, huésped y otras palabras que menciona, son excepciones a la ley de caída de postónica porque se trata de palabras semicultas. En 1940 ( § 26.3) el mismo problema de la pervivencia de la postónica, le sugiere una reflexión teórica sobre el modo de funcionamiento de las leyes fonéticas que va más allá de la teoría de los neogramáticos: «Juzgando fatales y mecánicas las leyes articulatorias, sin tener en cuenta los sincretismos que cada una admite, se ha pretendido buscar razones puramente fonéticas para la conservación de algunas de estas vocales postónicas; se alegó, por ejemplo, la dificultad de articular el grupo triconsonántico resultante en HOSP(I)TЕ 
CESP(I)TE , pero tal dificultad fue resuelta fácilmente en hostal y en infinitos otros casos que ofrecen los grupos secundarios de consonantes. Además del cultismo puede intervenir alguna otra razón no fonética: en HOSP(I)TE el derivado tradicional sería * hueste, cuya homonimia con el derivado de ноsтis le condenaba a perecer $»$.

En esta reflexión Menéndez Pidal afirma que las leyes fonéticas pueden estár sometidas a suspensión o neutralización, lo que él llama sincretismo. Esta explicación intuye la idea , luego sostenida por algunos fonólogos generativistas, como C.Kisseberth ( 1970), de que las reglas fonológicas constituyen una unidad funcional de modo que pueden suspenderse cuando producen resultados que infringen las restricciones fonológicas de la lengua. Si la aplicación de las leyes fonéticas producen conglomerados consonánticos no permitidos por el patrón fonológico de la lengua, como -spd, entonces queda suspendida la ley de pérdida de la postónica interna ,y se produce así un resultado conforme con el patrón fonológico, como huésped. El sincretismo de las leyes fonéticas es un factor funcional, no articulatorio, que restringe la actuación de estas leyes.Como no podía ser de otra manera, Menéndez Pidal recurre al concepto de (semi)cultismo como factor que puede suspender la aplicación de una ley. La misma función hay que atribuir al concepto de hominia, introducido por J. Gilliéron ( 1918), al que Menéndez Pidal se acoge también para explicar el resultado de la evolución de HOSP(I)TE .

En conclusión, el «Manual de Gramática Histórica » de Menéndez Pidal supuso la inclusión de España en la corriente científica europea del siglo XIX en fecha algo tardía, en 1904. No obstante, fue un trabajo seminal que entre 1904 y 1940 el autor revisó y corrigió, una prueba de su honestidad científica y de su esfuerzo por la exactitud en la elaboración de una gramática histórica científica . El seguimiento de la reelaboración de sus ideas de 1904 hasta 1940 ofrece ocasión para penetrar en la forja del pensamiento lingüístico de uno de los filólogos más originales y polifacéticos del siglo XX.

Menéndez Pidal empezó el « Manual » como neogramático y lo terminó como neogramático, pues nunca negó explícitamente el concepto de ley fonética, como lo hizo Schuchardt. Pero fue un neogramático con reservas y precisiones importantes, y que cada vez más daba entrada a factores sociolingüísticos, (socio)históricos, funcionales y estéticos. Éstos últimos en la dirección que Karl Vossler ( 1904 ), siguiendo al Croce de la « Estética », de 1902, quería para la lingüística. En la elaboración del «Manual» hay dos fases:la primera abarca desde 1904 a 1918.En esta ha 
diseñado el esquema básico en términos de leyes fonéticas y de excepciones explicables a las leyes dentro delmarco neogramático.

En la segunda fase, desde 1925 hasta 1940, el « Manual » da cabida tanto a la teoría del tradicionalismo como a factores estéticos, sociolingüísticos y (socio)históricos. El cambio lingüístico, afirma, no es entre dos generaciones, tesis neogramática de Paul, sino en una consecución de larga duración entre generaciones. Tampoco da entrada Pidal al aprendizaje de la lengua como factor del cambio lingüístico, al contrario de lo que afirma Paul. Para Pidal, las leyes fonéticas están sometidas a causas no sólo psicológicas, sino sociológicas e históricas como el contacto de lenguas, el sustrato, el gusto lingüístico, o la ultracorreción. Esto aleja a Menéndez Pidal de las tesis rígidas de los neogramáticos, como más tarde, en las décadas de 1950 y 1960 , del estructuralismo diacrónico de Martinet.

A pesar del siglo transcurrido desde su primera edición y de los más de sesenta años desde la última revisión en 1940, y aun siendo un texto científicamente del siglo XIX, creemos que esta obra permanecerá como fuente indispensable de inspiración y de formación para próximas generaciones de hispanistas. 


\section{NOTAS}

1. H.Paul, Prinzipien der Sprachgeschichte. Seis ediciones revisadas por el autor desde 1880 a 1920.Sigo la de 1886 y la de 1920, reeditada por Niemeyer, Tübingen, 1975.

2. Las ediciones del «Manual de Gramática Histórica » que he consultado son las siguientes:1 $1^{\underline{a}}$ edición de 1904 con el título de «Manual Elemental de Gramática Histórica Española » Madrid, Librería General de Victoriano Suárez; $2^{\text {a }}$ edición , 1905, con el mismo título,lugar y editor; $3^{\text {a }}$ edición, 1914, idem, idem; 4ª edición,1918, cambia el título a « Manual de Gramática Histórica Española », Madrid, Librería General de Victoriano Suárez ; 5ª edición ,1925, idem , y $6^{\text {a }}$ edición,1940, Madrid, Espasa-Calpe.

3 .La analogía es un proceso compartido también con los paleogramáticos.

5. También lo emplea Cuervo (1905), nota 104 a la Gramática de Bello. La versión definitiva de las notas de Cuervo se publicó en 1898, según Homero Serís . El filólogo bogotano absorbió impecablemente la doctrina neogramática de Hermann Paul, cuyos «Prinzipien» menciona con frecuencia en las Notas, así en la número 8, 70 etc.

6.E. Förstemann (1852) 


\section{BIBLIOGRAFIA}

Alemany, José, Estudio elemental de gramática histórica de la lengua castellana,Madrid, Tip. de la Revista de Archivos, Bibliotecas y Museos , 1902.

Commelerán, Francisco, Gramática comparada de las lenguas castellana y latina, Madrid, Agustín Jubera, ${ }^{2} 1897$.

Croce, Benedetto, Estetica come scienza dell'espressione e lingüística generale, Milano, R.Sandron.

Cuervo, Rufino José, Notas a la Gramático de Andrés Bello, Paris, Ay R. Rogier y F.Chernoviz, 1905

Förstemann, Ernst, Über deutsche Volksetymologie, Zeitschrift für vergleichende Sprachforschung, 1, (1852), 1-25.

Gauchat, Louis, Confussion d'occlusives dans le patois de la Suisse romande, en : Homenaje a Menéndez Pidal ; miscelánea de estudios lingüísticos, literarios e históricos, Madrid, Hernando, 1925

Gilliéron, Jules, Généalogie des mots qui designent l'abeille d'après l'Atlas liguistique de la France, Paris, Champion, 1918

Gröber, Gustav, Grundriss der romanische Philologie, I Band, Strassburg, Karl J. Teubner, 1888 .

Jakobson, Roman, El folklore como forma específica de creación, en: Roman Jakobson, Ensayos de poética, Madrid, Fondo de Cultura Económica, 1975,7-22.

Kiparsky, Paul, Linguistic universals and linguistic change, en: E.Bach y R. Harms, Universals in linguistic change, New York, Holt,1968 
Kisseberth, Charles, On the functional unity of phonological rules, Linguistic Inquiry,I-1 (1970), 291-306.

Menéndez Pidal, Ramón, Orígenes del español, Madrid, Centro de estudios históricos, 1926.

Meyer- Lübke, Wilhem, Grammatik der romanischen Sprachen, Leipzig, Fues's (R.Reissland) 1890.

Meyer-Lübke, Wilhem, La sonorización de las sordas intervocálicas en español. RFE , XI, (1924), 1-32.

Panconcelli-Calzia, Giulio, Die experimentelle Phonetik in ihrer Anwendung auf die Sprachwissenschaft, Berlín, W .de Gruyter , ${ }^{2} 1924$.

Ramón y Cajal, Santiago, Textura del sistema nervioso del hombre y los animales, Madrid, N.Moya, 1899.

Paul, Hermann, Prinzipien der Sprachgeschichte, Tübingen, Niemeyer ,1975 ( 1880)

Saroïhandy, Jean, Vestiges de phonétique ibérienne en territoire roman, en :Revista Internacional de estudios vascos, VII, (1913), 475-497.

Schuhardt, Hugo, Baskisch und romanisch, Beiheft zur ZfRP, 6, Halle a.S., Niemeyer,1906.

Schuhardt, Hugo, Die iberische Deklination, en: Sitzungsberichte der Wiener Akademie,CLVII, (1907), 1-90.

Szemerény, Oswald, Introducción a la lingüística comparativa, Madrid, Gredos, 1978.

Vossler, Karl, Positivismus und Idealismus in der Sprachwissenschaft, Heidelberg, C.Winter,1904.

Wartburg, Walter von, Problemas y métodos de la lingüística, Madrid, CSIC, 1951. 
